\title{
MIRANDO POR SOBRE LA TAPIA
}

La palabra deconstructivismo se escucha cada vez con mayor frecuencia en aulas universitarias y reuniones de arquitectos, precisamente en un momento en que otra palabra ya desgastada- la palabra post-modernismo pareciera quedar relegada a los anaqueles de ventas por liquidación de mercadería. Pareciera entonces que esta nueva y misteriosa palabra llena un vacio cerrando un paréntesis en el debate arquitectónico.

Quieroreferirme al deconstructivismocomo fenómeno arquitectónico y no filosófico, pictórico o literario por desconocer casi enteramente su proyección en estos otros ámbitos.

La palabra deconstructivismo resuena con actualidad y se difunde a través de los medios de comunicación. Para Jorge Glusberg crítico argentino se trata de "una gran interrogante quizás tan grande como la que surgió en 1932 cuando Philip Johnson presentó en el MOMA aquella exhibición internacional que promovió el surgimiento del International Style" ..

Esta creatura recién nacida tiene para Glusberg una fuerza potencial equivalente al movimiento que remeció las fundaciones de la arquitectura en la primera mitad del siglo.

Pero Glusberg no se atreve a apostar con certeza acerca del futuro de esta nueva Escuela. Tal vez sea asi porque los críticos sufren hoy en día de un frenesí taxonómico: Charles Jencks el crítico que con mayor fervor y eficacia promovió el post-modernismo, construía árboles genealógicos, establecía clasificaciones nuevas, ubicaba autores y obras en un cuadro tan complejo y entrecruzado como un circuito de computación.

El libro "Arquitectura Post Moderna" de Jencks que circuló en Rusia (pre-Glasnost) y China y por lo tanto también en todos aquellos lugares de más fácil acceso, se encuentra hoy en día en estanterías de liquidación y librerías de segunda mano. Se publicó el año 77 , no alcanzó a mantenerse vigente más allá de 13 años. En la penúltima página publica el AT \& T. rascacielos en Nueva York, el asi llamado rascacielos Chippendale aludiendo a su cornisa superior. Jencks citando a un crítico que lo consagra como "el primer gran monumento del post-modernismo", se pregunta si se tratará de un monumento inaugural o del féretro del movimiento post-modernista.

Philip Johnson, el mismo Philip Johnson que organizó la muestra de arquitectura moderna del año 1932, el mismo autor de una arquitectura monumental que bordea o entra de lleno en el Kitsch, cierra su carrera pública ya viejo con la exposición del Deconstructivismo. Bajo ese llamativo título invita a exponer a un grupo reducido de arquitectos. ¿Quienes son? Frank Gehry californiano, Daniel Libeskind polaco. ex director del curso de post grado en Cranbrook, USA., Rem Koolhaas holandes radicado en Londres, Zaha Hadid iraquí también radicada en Londres, Peter Eisenmann neoyorquino. Bernard Tschumi, suizo francés ahora radicado en Nueva York y Coop Himmelblau, cooperativa austríaca radicada en Viena.

Libeskind, Koolhaas, Tschumi, Hadid enseñaron en el Architectural Association, Londres. Wolf Prix de Coop Himmelblau estudió alli, Peter Eisenman estudió un post-grado en Cambridge y mantiene estrechos vínculos con la AA. Las relaciones personales existen sin garantizar una comunidad de ideales. Frank Gehry es caso aparte. ¿Qué piensan estos caracteres? Libeskind actúa como alquimista en el área de los conocimientos herméticos.

Koolhaas, Tschumi y Hadid estudian distintas facetas del constructivismo ruso. Peter Eisenman hace de cada proyecto una tesis acerca de la naturaleza del objeto arquitectónico. Coop Himmelblau crea arquitectura a partir de un proceso análogo a la escritura automática de los surrealistas. Frank Gehry constructor más que teórico ironiza. Otros podían haber sido invitados y no lo fueron.

Pero, ¿existe en ellos una comunidad de ideales, una escuela? No me atrevo a decir que sí. Con certeza puedo asegurar que el nombre de Derrida, filósofo francés a quien Glusberg consagra como "padre del deconstructivismo" no ha tenido mayor injerencia en la obra de Zaha Hadid ni de Rem Koolhaas ni de Frank Gehry ni seguramente en la obra de Coop Himmelblau.

Existen tal vez semblanzas: la filiación constructivista, el antihistoricismo, un anticlasicismo... si construír deconstruyendo equivale a desafiar el rol tectónico de los elementos, descuadrar, desencajar, derivar, hay sin duda más de alguna similaridad. ¿Suficiente para proyectarse como movimiento, escuela, origen? Creo que no.

\section{Milan Kundera dice:}

"la cultura es la guardiana de la memoria. los medios de comunicación persiguen la actualidad. Pero la actualidad es un acontecimiento destinado a ser olvidado rápidamente. Un mundo obsesionado por la actualidad es un mundo obsesionado por el olvido. En este "sistema de olvido" la obra de arte se convierte en un gesto sin futuro".

Estas terribles palabras de Kundera me parecen de especial vigencia. El "deconstructivismo" acaba de ser proclamado: Sólo algunos de los invitados a la celebración en el MOMA se sabían deconstructivistas.

¿Y por que se nos convoca a nosotros aquí en esta escuela a discutir el deconstructivismo? me pregunto si cuando nos reunimos así no estaremos desesperadamente tratando de mirar por encima de una tapia a unos vecinos que organizan una monumental juerga de la cual solo escuchamos ruidos y atisbamos fuegos artificiales extraños nunca antes vistos. Vecinos y no invitados, no participantes ni gestores.

Los arquitectos en Chile somos -reconozcámoslo- seres perfectamente marginados. La arquitectura en su dimensión más verdadera y profunda no constifuye una preocupación en nuestra cultura. Nosotros, vecinos perennemente atisbando por encima de la tapia al más allá, vivimos un medio en el cual nociones tan básicas como espacio público y monumento no tienen mayor resonancia.

Si el deconstructivismo se lee por lo menos a un nivel como una estrategia del desconcierto análoga al acto de Duchamp de ubicar un urinario en un pedestal de museo -legitimado como un modo potente y eficaz de llamar la atención hacia el significado del arte, nosotros podemos tal vez colocar urinarios en pedestales pero carecemos de un marco análogo al museo, del espacio consagrado en la cultura y las aspiraciones colectivas frente al cual la provocación adquiere resonancia.

No ocurre así con los invitados a la fiesta. Los europeos actúan en un medio cultural en el cual se reconocen fuertes cualidades. El parque de la Villette existe después de todo en Parísy proclama su idea de parque en contraste con una riquísima tradición de parques y de lo público. Los americanos han inventado fenómenos como Nueva York y los Angeles, lugaresimbuídos de la fuerza que una idea adquiere al ser llevada al límite de lo posible. Nueva York el paradigma de ciudad-metrópolis, Los Angeles el paradigma de ciudad-territorio.

¿Y nosotros? los que miramos por sobre la tapia (con un dejo de envidia) pensamos que seguramente las cosas seguirán ocurriendo del otro lado de la tapia, y además como ocurrió en el matrimonio de la Cecilia Bolocco con seguridad no llegaremos a ser invitados. 
Tal vez nos consolemos pensando que, además como aquí si hay terremotos que deconstruyen, tal vezno sea necesario deconstruir por anticipado.

La palabra deconstructivismo alude a la construcción, si como dice Glusberg se trata de "una arquitectura de desvios" y además de una arquitectura antigravitacional-tal vezmás claramente expresada en la obra de Coop Himmelblau- esta arquitectura supone una destreza técnica impresionante. Se trata de desviaciones calculadas de equilibrios precarios, de sistemas de alta precisión. Para nosotros que vivimos rodeados de imprecisiones y descuidos, en ciudades que tienen tantas lineas de edificación como hubo alcaldes, estas sutilezas, no pueden llegar a tocarnos el alma. Suspendida por sobre nuestras cabezas se perfilan dos grandes preguntas: ¿es real el deconstructivismo como escuela? y la segunda

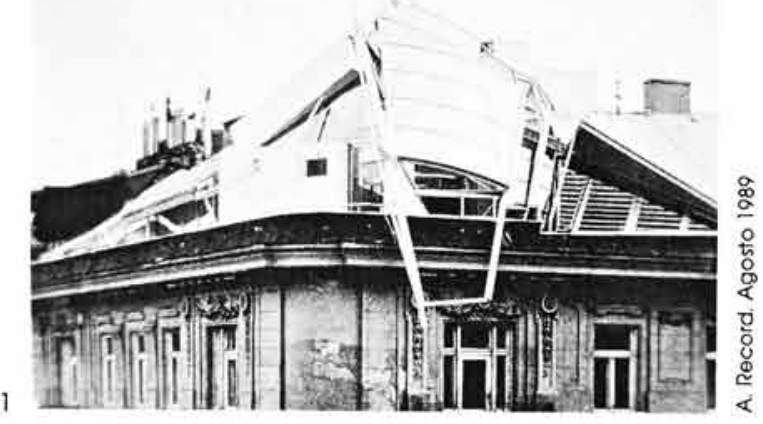

más amenazante: "¿Y después qué?"

Tal vez sea al fin y al cabo ventajoso encontrarse al lado de acá de la tapia. Sin caer en provincialismo ni aún peor en nacionalismo algún dia podremos formularnos nuestras propias preguntas, preguntas que tal vez calen hondo en una cultura como la nuestra en la cual la arquitectura no merece más que algún espacio en suplementos de decoración de interiores.
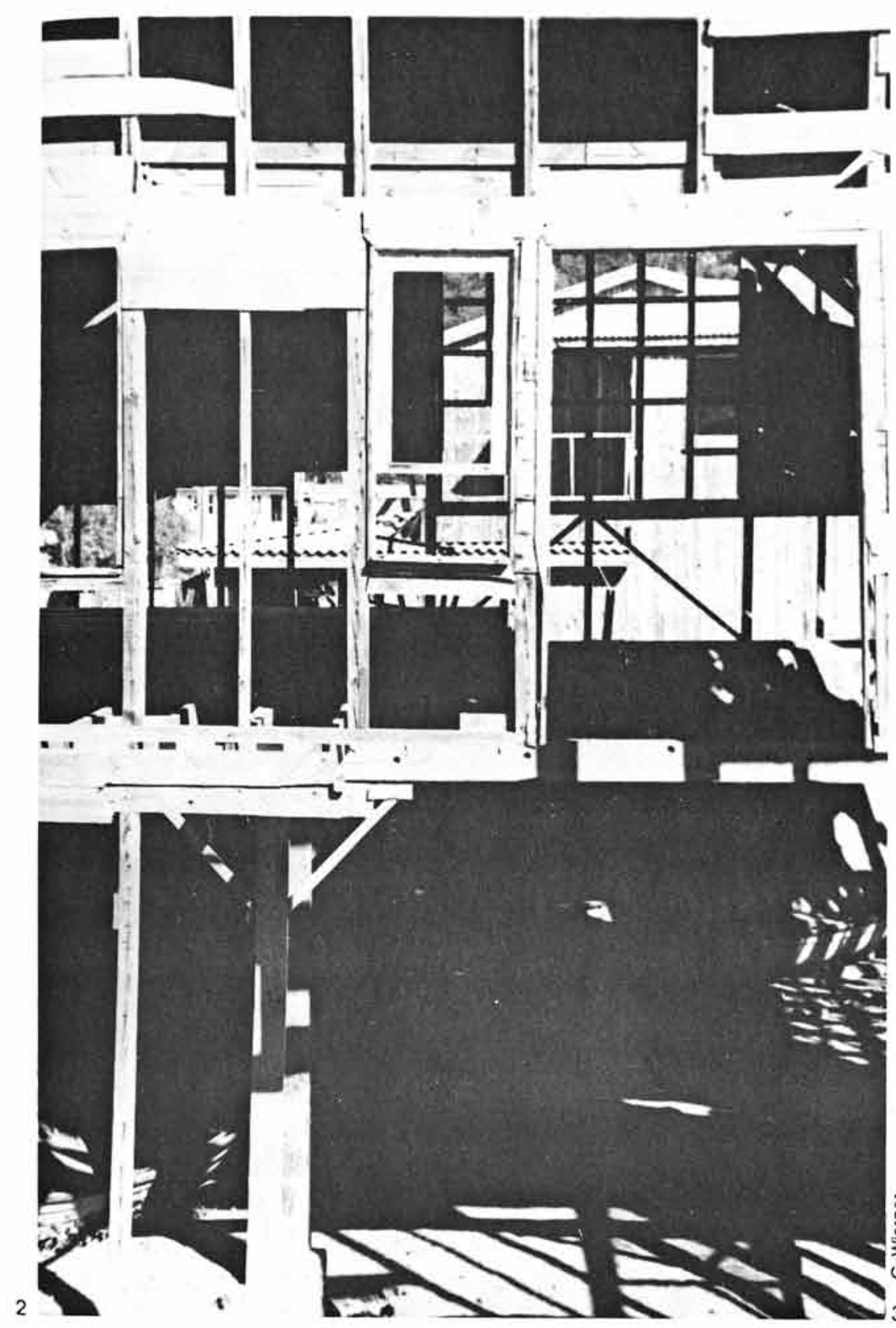

$x-\infty$ 